\title{
Article
}

\section{Making meaning in muddy waters: representing complexity through community based storytelling}

Little, Robert Matthew and Froggett, Lynn

Available at http://clok.uclan.ac.uk/3336/

Little, Robert Matthew and Froggett, Lynn ORCID: 0000-0001-8406-6231

(2009) Making meaning in muddy waters: representing complexity through community based storytelling. Community Development Journal, 45 (4). pp. 458-473. ISSN 0010-3802

It is advisable to refer to the publisher's version if you intend to cite from the work.

http://dx.doi.org/10.1093/cdj/bsp017

For more information about UCLan's research in this area go to http://www.uclan.ac.uk/researchgroups/ and search for <name of research Group>.

For information about Research generally at UCLan please go to http://www.uclan.ac.uk/research/

All outputs in CLoK are protected by Intellectual Property Rights law, including Copyright law. Copyright, IPR and Moral Rights for the works on this site are retained by the individual authors and/or other copyright owners. Terms and conditions for use of this material are defined in the policies page.

\section{CLoK}

Central Lancashire online Knowledge www.clok.uclan.ac.uk

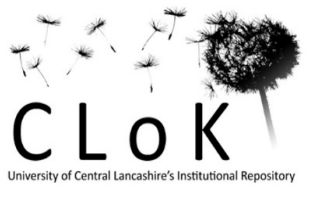


Title:

Making meaning in muddy waters: Representing complexity through community based storytelling.

Little, R.M. \& Froggett, L. (2009) Making meaning in muddy waters: representing complexity through community based storytelling. Community Development Journal, 45, 4, 458-473.

Abstract:

Internationally, storytelling has been used with many diverse communities. This paper compares the use of storytelling as a participatory art-form within a community development project and a community and healthy living centre in the UK. Both the project and the centre regard storytelling activities as 'inclusionary' forms of intervention. However, the discourse of social inclusion rarely acknowledges the subtle psychosocial processes that are involved in participatory storytelling. This paper discusses such processes and examines some methodological implications of researching storytelling. It asks what contribution storytelling can make towards authentic representation of individual and community voices.

The professional storyteller Jack Zipes' views the 'basic functions' of storytelling as both conserving and challenging the values and norms of the group. For example, the narrative of the 'hero's journey' supports the post neo-liberal subject of active citizenship. However, this presents an overly simplistic tale of personal change which storytelling can challenge in subtle ways by narrative and performative devices, allowing glimpses of alternative subjectivities, based on recognition and 
interdependence. A resistance to simplistic representations of the hero’s journey places personal progress in collective contexts making it susceptible to unforeseen set-backs, influences and hubris, and ultimately dependence on others. This has implications for our valorisation of individual strength over vulnerability and activism over passivity. In the institutional domain it affects who is seen to bear responsibility for 'successful' project outcomes and has implications for the inclusiveness of organisational cultures.

\section{Introduction}

Throughout this article the term storytelling and narrative are conflated. This conflation reflects Polkinghorne’s (1988) view that narrative is the primary form people use for organising their experiences into temporally located, meaningful 'episodic units'. It can refer to both the cognitive processes which underpin the creation of a story and the results of these processes: the story itself (ibid, p.l3). Similarly, Bruner (1986) sees narrative as a 'mode of thought' that involves making meaning in contrast to 'logico-scientific' thinking. Meaning generating narrative is the medium of the 'folk psychology' that drives behaviour in our social institutions (Bruner, 1990). Storytelling or narrating as understood here refers to a mental process of organising experience which is in a meaning driven, reciprocally constituting relationship with culture. It is central to how people construct and understand their experiences.

This article draws on two separate research and evaluation projects carried out by the authors to examine aspects of storytelling - firstly, in the temporary organisation of a community development project and, secondly, in a mature community based 
organisation. In both cases storytelling, formal and informal, was found to be a prime means of cultural transmission, mediating the perceptions of others and the interdependencies within the communities by allowing a complex and ambivalent view of aspirations, actions and motivations. This complex view challenges a simplistic rendering of the ‘hero’s journey’ story. The hero’s journey is played out repeatedly in the hour-long narratives of television programs; in the short biographies which accompany the smiling faces in brochures advertising university courses; in Hollywood blockbusters; and in the rhetoric of policy documents (Blair, 2006; 2006a LSE, 2006). The narrative involves the protagonist engaging in a sustained period of effort which results in significant and what are often portrayed as life-changing rewards. After the period of struggle, the journey, the hero is almost unquestioningly depicted as feeling and being better. Emotional experience is therefore, split into a before and an after. There is a teleological element to this narrative, an implicit sense that personal struggle will result in meaningful benefits, indeed morally just rewards. It is a view which has historical precedence in widely divergent sources: the book of Job, the Iliad, the New Testament (Bowker, 1997), and much fictional literature. This narrative of individual strength in the face of adversity, and the separation of emotional experience is challenged by the evaluations of the two community projects discussed here. Such an analysis however, can only emerge when evaluation methodologies are narrative-sensitive and allow the stories to yield up their store of fantasies, conflicts and paradoxes and hence shed light on the complex subjectivities of both narrators and audiences. 
As a cultural artefact storytelling has an ancient history. However, Zipes (2006) has located the recent revival of storytelling as an art form in a specific socio-historical context: the political activism of the late 60’s. He sees it as emerging from the civil rights and anti-Vietnam war movements as part of the “...struggle for truth and to expose the hypocrisy of the so-called industrial-military complex" (ibid, p.xviii). One of the most prominent commentators on contemporary storytelling, Michael Wilson, maintains that the revival is best understood as a 'branch of alternative theatre' that seeks to challenge bourgeois mores and democratize the arts (Wilson, 2006). For Zipes the two basic functions of storytelling are:

“...to communicate the relevant values, norms, and customary practices of a group of people, to conserve them and pass them on...to question, change and overthrow the dominant value system, to transform what has been preserved"

(Zipes, 2006, p.xv).

If there has been a 'turn' towards storytelling as a democratic force - whether driven by a radical agenda or a more general attempt to tackle social problems such as exclusion - evaluation of storytelling projects should acknowledge this potential. Zipes (2006) 'basic functions’ of storytelling focuses attention on the ability of storytelling to encourage participation, a sense of belonging and a sense of contributing to, or being able to challenge, wider social and cultural discourses. Wilson (2006) describes this as a form of ‘cultural egalitarianism', possibly a sustaining force in participatory democracy and congruent with Greenwood \& Levin's (2005) understanding of 'participative democracy as both a method and a goal' (ibid, p.53). Storytelling seems well equipped for this role. In allowing the 
space for narration to occur, the voices of those regularly marginalised are able to participate in the processes of social and political change (Chase, 2005), and there is evidence of its use internationally. For example, through collecting stories from women about their bodies and using the stories as the basis of a Broadway production ('The vagina Monologues'), Ensler (2001) contributed to the growth of an international movement which campaigns to stop violence against women. Similarly, Augusto Boal's 'Theatre of the Oppressed', which encourages audience members to decide upon the direction of the narrative on stage, such as altering an oppressive relationship, encourages audience members not only to imagine change but also to practice that change in their lives (Boal, 1985).

Storytelling has illuminated variations in experiences of identity across different nationalities. For example Pakistani women were found to equate personal stories of suffering with an honourable identity (Grima, 1991). Significantly, when recounting their life stories, individuals who lived in Eastern Berlin before and after 1989, used the process of narrating to reconfigure their past identity so that it made sense from the perspective of the present (Andrews, 2000). Importantly, Chase (2005) emphasises that 'self or identity' may not play a central role in some Non-Western narratives. Storytelling may therefore allow Non-Western narratives to be articulated, and used to generate greater understanding of how the relationship between self and society is conceived in Non-Western cultures. 
The ubiquitous nature of storytelling may allow it to access and express certain experiences in a manner other forms of communication are less able to do, building on the interactional and representional processes in everyday communication, a condition of 'communicative democracy' (Young 2000) The Psychosocial Research Unit (PRU) at the University of Central Lancashire has evaluated several projects which have used community based storytelling in various forms. Two of these projects will be now be examine to show how storytelling maintains and challenges entrenched cultural values.

\section{The Todmorden Touchwood project}

Todmorden Touchwood set out to generate a multi-media, multi-stranded narrative involving stories, poetry, music, illustrations and textiles that could represent the diverse identities of $21^{\text {st }}$ Century Todmorden. It attracted funding as a 'social inclusion' project, a somewhat over-generalised concept based in this case on the understanding that diverse sections of the community would be involved in activities which would work towards establishing a distinctive and by implication 'unified' Todmorden identity. In fact the effects of the stories were often more psychologically complex and subtle than the discourse of social inclusion allows, necessitating both emotional and micro-political labour in their development and in their telling.

One of the tangible legacies of the project has been the illustrated web-site with the artists' blogs, a tree showing participating schools and a quirky collection of Todmorden 'urban myths'. Todmorden is a small town with a population of approximately 12,000 that exists on the border of Lancashire and Yorkshire. The 
website describes how with its Lancashire postcode, Todmorden which is geographically in Yorkshire, is used to being 'out of place'. It is a picturesque location which has regularly appeared in television series including: The League of Gentlemen and Life on Mars. Todmorden has slightly lower levels of ethnic minorities that the national average. However, these communities are well established and include a small Asian community and a small Polish community (ONS, 2001). Despite its natural beauty Todmorden has been identified as an area suffering from serious social deprivation and scores highly on several deprivation indicators including: smoking related deaths, drug use, number of conceptions in the under 18's and the number of children living in overcrowded conditions (DH, 2006; ODPM, 2004).

The Todmorden Touchwood project involved several artists working with classes of schoolchildren from the eight primary schools, and single secondary school in Todmorden. The project also ran weekly sessions at the local community centre. These sessions ran on a drop in basis and were attended by working mothers, single mothers and members of the Asian community (there was an interpreter provided for many of these sessions). The project consciously worked towards final performance events which included a poetry slam at one of the schools and an exuberant finale which brought together all participant groups. The project was evaluated on a shoestring budget by PRU and under constraints which precluded the use of depth methodologies, such as will be described later in this article. Nevertheless, a combination of interviews, observations and the collection of stories produced a good overview of the work of the different artists and the nature of the childrens' and wider public engagement. 
The professional storytellers included Shonaleigh of Jewish/Dutch descent and Peter Chand whose parents were of the 1950’s wave of Indian immigrants. Craig Bradley, who has adopted 'that poetry bloke' as his moniker is Yorkshire born and bred, but his claims to marginality include a chequered career as gravedigger, stand-up comedian, teacher and writer. These three were employed by the local storytelling group - Shaggy Dog Storytellers - who had received Heritage Lottery funding. All used highly participatory techniques designed to draw the audience into story-making. Shonaleigh's style, for example, was to involve the audience in the production and evolution of the narrative by continually interrogating the audience and prompting reflection with questions like 'Why did this happen?' The stories generated were primarily morality tales which drew on the local mythology of Todmorden and used landmarks and folktales to create a rich verbal tapestry of the area, which then found a counterpart in the visual textile art of the project directed by Graham Higgins and Denise Oukhaba. The narratives involve the repetition of the themes of love, loss, choice, sacrifice, friendship, punishment, justice and redemption. The stories adhered to a traditional narrative form: introduction - complication - resolution (Wilson, 2006). However, what emerged consistently in the contributions made by the community members was that these resolutions were rarely unambiguous (see www.todmordentouchwood.com). One of the stories produced in the project was 'The Stones at Dobroyd'.

\section{The Stones at Dobroyd}

The story tells of a poor but happy couple, George and Rebecca, who live on the land near Todmorden with their ever faithful horse Hercules. The couple long for a child and when George voices his wish out loud one day, the local fairies offer to grant it. George hastily agrees without realising the fairies 
want Hercules' heart in return. George is greatly anguished when the truth dawns but the deal is set and when the time comes Hercules meets with the fairies and is turned to stone looking out over the landscape in the 'top field'. Each year the family lays flowers at the base of the stone statue in thanks.

The child, Edwin, grows up and leaves his parents to work in Halifax. One day he returns home for a visit. Opening the door, he finds food on the table and logs in the grate. But there is no sign of his parents. Searching for them, he eventually comes to the top field, where he finds two large upright stones, the size of people, leaning into each other as if caught in an embrace.

(from the 'Stones of Dobroyd')

Within the narrative George and Rebecca's 'dust to dust' return to the earth is not over-dramatised, or represented as tragedy. The return to stone is seen as part of the cycle of life and death, suggested by imaginative association to local landmarks, embodied in the growth, decay and petrification of nature and accommodated within the cycle of the narrative

Stories like this demonstrate how, even when working with a predominantly school age audience, the tensions around death, betrayal and the motives of 'others' can resist blandly optimistic or catastrophic endings and generate a philosophical and reparative turn of mind. The resolutions of many of the Todmorden Touchwood stories are typically anti-heroic eschewing superhuman strength, or remarkable feats of courage or ingenuity. Personality traits such as vulnerability, stubbornness, stupidity and prejudice are not projected onto the 'bad' but are to be found in all, and by implication therefore within ourselves, just as all can partake in moments of nobility, self-sacrifice and generosity. People, in short, are mixed: foolish, mean, kind and clever by turns and they deserve an ambivalent, complex appraisal, the 
suspension of rash judgement, the blessing of forgiveness and the right to recognition within an inclusive community.

Todmorden Touchwood was conceived as a community inclusion initiative, aiming to knit together the strands of Todmorden’s heritage and - principally but not exclusively through its schools - some of its diverse communities. What role do stories like the Stones of Dobroyd play in such a project which if it is to afford an opportunity for moral learning and bridge divisions, needs to capture the moral imagination and relate to a wide societal context. In fact storytelling always gives voice, often unwittingly, to tacit assumptions about self and others which are embedded in the political and social environment (Wilson, 2006). In Zipes’ terms, storytelling should both transmit the values and norms of a particular group whilst also being able to unsettle and prise open contradictions. The pervasive nature of the hero's journey narrative in its simple form, which suggests that sustained individual effort will reap unequivocally positive rewards, is clearly at odds with this function.

The spontaneous manifestation of the hero's journey narrative suggests that storytelling, when intended as a tool for challenging social inequalities, can be assimilated and rendered supportive of current political and cultural mores. The hero's journey appears to be a message of hope for those experiencing adverse conditions, a story whose essential subtext is 'keep going, it will be worth it in the end'. However, the pervasiveness of this message raises the question as to whether this maintenance of hope in the face of all adversity encourages political quietism as the culture industry serves to promote the hegemony of dominant groups who have much to gain from a continuation of the status quo (Zipes, 2006). What emerged in the Todmorden 
Touchwood project was the potential of anti-heroic storytelling to reveal ambiguities and emotional complexity and therefore challenge the resolution-focused nature of the hero’s journey.

\section{Storytelling in the Bromley by Bow Centre and in-depth methodologies}

The Bromley by Bow community, healthy living and children's centre has been identified by government, and within an EU funded international study as a 'flagship' of social enterprise. It has a history of successfully integrating health and social care within a holistic model of well-being. The Centre attracts a wide range of age-groups and is used by the many different ethnic communities that make up the population of the surrounding borough. In common with many other such centres there is a particular emphasis on involving potentially excluded groups such as the elderly and profoundly disabled, but what for our purposes sets it apart is its claim that for much of its history the arts have been central to its approach to health, leisure, enterprise and social care. This arts based approach is sustained and nourished by story-telling woven into its organisations mythology as well as into the warp and weft of its everyday life.

The Todmorden Touchwood evaluation was methodologically straightforward, concentrating on the content of the stories and the children's and community's observable reactions. Even so, by producing stories which required a moral effort it induced the children to grapple with a complex view of subjectivity and otherness. In the much larger Bromley by Bow project the possibility of adopting a depth methodology allowed the researchers to trace the links between organisational culture and the complex subjectivity of its members and hence to make bolder claims. 
The overwhelmingly pervasive story form was the 'bildungsroman' - the story of personal progress caste as a narrative of entrepreneurial heroism. Given the relative deprivation of the Borough of Tower Hamlets this was superficially a journey involving progress won through struggle against the odds. However, there were other less triumphalist currents both in the content and form of the telling. These portrayed a more equivocal ‘heroism' within a caring community which could discover resources within their vulnerability and brokenness. This version was ultimately closer to the reality experienced by most people who attended the Centre, and more personally enabling as can be seen in 'Nell's' story.

\section{Emergent methodological issues}

When researching community cultures - particularly arts-based story-telling cultures the challenge is to develop arts and story congruent methods. It is relatively straightforward to analyse plot and extract the themes and tensions as we have done in the case of Todmorden Touchwood. However, if we are to fully understand the work that story-telling does in relating the lives of individuals to their communities we need to sensitise ourselves to the artifice of the telling - its performative dimensions. In order to do this we bring into our analytical frame our own aesthetic apprehension of the story: re-telling it, and comparing our versions with our record of the original, to understand its claims to authenticity and how it mediates between personal idiom and cultural imagination.

Nell's story is reproduced here in two different forms. In the first version it appears as it was digested and organised by the original researcher (Lynn Froggett). This is 
contrasted with the spontaneous re-telling by the co-author of this paper (Rob Little).

Unlike Lynn, Rob was not involved in the original research and hence had no direct

relationship with the Centre or its members. He has never met Nell.

\begin{tabular}{|c|c|}
\hline Nell’s Story: Lynn’s version & Nell's Story: Rob’s version \\
\hline $\begin{array}{l}\text { Nell is now in her early seventies and her health } \\
\text { has suffered much over the years: diabetes, } \\
\text { enlarged thyroid, asthma, reduced mobility, } \\
\text { neurological problems. Her story is moulded by } \\
\text { the conditions and needs of others with problems } \\
\text { more severe than her own, whose demands for her } \\
\text { care have been insistent. Her account of, work and } \\
\text { achievement before coming to the Centre is spare } \\
\text { in the extreme. She offers nothing on her } \\
\text { childhood except its termination. At } 13 \text { she leaves } \\
\text { school for a succession of jobs. Only office } \\
\text { cleaning is named. Her mother suffers a stroke and } \\
\text { Nell nurses her for twenty years combining this } \\
\text { with parenting and more work. At times her } \\
\text { patience is tested as she struggles with her own } \\
\text { frustration. Later, as her health deteriorates, she } \\
\text { copes with her husband's prolonged decline from } \\
\text { Alzheimer's. He is confused and resentful. He } \\
\text { throws himself from his wheelchair and accuses } \\
\text { her of pushing him. She is lucky to be among } \\
\text { people who know and trust her. She is widowed. } \\
\text { So pass her youth and middle-age. } \\
\text { In the Centre Nell has become part of a } \\
\text { community, a 'we'. As patient in the group } \\
\text { practice she meets with respect and } \\
\text { responsiveness: her anxieties are recognised, } \\
\text { things are explained. She identifies with the } \\
\text { Centre's projects, organises, speaks for it with a } \\
\text { new-found authority. She progresses from } \\
\text { 'member' to 'volunteer', discovering in herself the } \\
\text { ability to work well with people who others find } \\
\text { strange and difficult. She explores pottery and } \\
\text { painting, but finds her medium in mosaics. She } \\
\text { becomes a group-leader, sits on interview panels, } \\
\text { studies for an NVQ, appears on TV, informs } \\
\text { professors, hobnobs with visiting royalty. }\end{array}$ & $\begin{array}{l}\text { Nell who is in her seventies has a history of } \\
\text { health problems including: asthma, diabetes, } \\
\text { mobility and neurological problems. Nell's } \\
\text { biographical account describes a life of almost } \\
\text { continual caring for those around her, particularly } \\
\text { her mother and her husband during his } \\
\text { deterioration due to Alzheimer's. This life of } \\
\text { caring means Nell has had very little formal } \\
\text { education and has predominantly been employed } \\
\text { as a cleaner. At her daughter's suggestion Nell } \\
\text { begins attending the centre. She participates in } \\
\text { the different arts classes, which she finds she } \\
\text { enjoys. Nell also finds herself regularly helping } \\
\text { others in the classes. Nell's ability to help others } \\
\text { is recognised and results in her being asked to } \\
\text { become a volunteer at the centre. Nell 'blossoms' } \\
\text { in the role of volunteer and after a period of time } \\
\text { is promoted to the position of group leader. Nell } \\
\text { enjoys the sense of responsibility associated with } \\
\text { this role and since taking on this role has become } \\
\text { a highly active and valued member of the } \\
\text { community. In her new role Nell has begun } \\
\text { formal education and regularly enjoys } \\
\text { 'hobnobbing' with politicians and academics to } \\
\text { speak about the Centre. }\end{array}$ \\
\hline
\end{tabular}

Both accounts are clear and economical summaries, but whereas Rob’s conveys the essential information, Lynn's has prosodic features that derive from an appreciation of the life she is trying to convey. Rob’s version is informative, no more no less. Lynn's, while not excessively embellished could have been crafted although in fact it was 
written 'as it came'. It has form and rhythm, and the aesthetic economy of the short sentences emphasise their understatement of markers, phases, events which have slipped away in a largely unnoticed life of private dramas submerged under the needs of others. Lynn reproduced Nell’s narrative in this form following her strong identification and sense of recognition in the interview and her subsequent immersion in the transcript. The Biographic Narrative Interpretive Method (BNIM) which was used in the study uses analytic protocols that leave space for reflexive emotional engagement as interpreters work in a panel (Wengraf, 2001). They are invited to speculate imaginatively on the meaning and gist of utterances before eliminating hypotheses as they proceed future-blind through the transcribed text. Eventually this procedure results in a structural hypothesis, for example in Nell's case the importance of recognition by others before personal change can take place. An innovation developed by the Bromley by Bow research team was also for interpreters to produce, when they felt ready, an appreciative syncretistic account which aimed to represent the distinctive aesthetic of the story and the life. Hence Lynn's version of Nell's story is not exactly how Nell told it. Rather it is grounded in Nell's telling, but based on what Nell told as Lynn experienced it. Its 'truthfulness' arises from moments of mutual attunement in the interview that allow Lynn to respond to Nell's embodied idiom as it seeps through the rhythms of her speech, the plainness of her phrasing and the empathic solidity of her presence. The elements of a hero story are overlaid with the older woman's self-deprecation. Rather than simply celebrating Nell's emancipation, Lynn's account enacts the understatement and finds in the endurance and in an ordinary capacity to care, a potential which is recognised and belatedly honoured within the Centre. 
BNIM initially prompts the interviewee to speak at length using a single question: in this case 'I would like you to tell me your life story, paying particular attention to how it has changed since you got involved in the Centre...' When the interviewee has had their uninterrupted say - which allows them to determine an order and system of relevance and narrative constructed meaning (Bruner, 1990; Polkinghorne, 1988) the interviewer then returns to significant themes in the biography, continually prompting the interviewee to develop stories around these themes. The assumption is that the inner logic and form of the story, together with conventions of performance exert their own 'pull', relaxing the conscious control of the narrator (Schütze, 1984). This lack of conscious control means the interviewee tends to reveal tacit assumptions (Polanyi 1966), which may tell us much about how they experience the political and cultural conditions in which the stories are embedded.

However, a personal story conveys more than social situation. When it is freely told, with minimal constraint or interruption, it is psychosocially significant: it bears the idiosyncratic imprint of the author. It is told a way peculiar to the narrator, according to a pattern or gestalt that they are unlikely to be aware of and this unwittingly seals it with the distinctive stylistic signature of a personal aesthetic. In the Bromley by Bow study the interpretive process went one step further to acknowledge a deep reflexivity whereby the interpreter also imprints the interpreted material in their own idiosyncratic and personally organised rendering of the text. The assumption here is that the 'pull' of the story's immanent logic arises because of its embodied nature and is revealed in its performance. This resonates with the listener, drives the interpretation and re-emerges in the retelling. The interpreted story is a co-creation, produced through an intersubjective exchange - or put more simply, the story has 
'passed through' both the narrator and the listener, acquiring on the way the idiom of each and the mark of their distinctive imaginative lives (Bollas, 1995). The narrator could perhaps tell it differently in another time or place, but no one else could tell in quite the same way, Similarly, with the interpreter who digests, re-embodies and retells the story, attempting to stay as close as possible to the spirit and feel of the original, yet inevitably infusing it with something of their own. The 'artfulness' of story-telling in research as in life arises from active and partly unconscious imaginative associations to the material and moments of attunement between teller and listener, as well as a cognitive faculty. What makes psychosocial research in this hermeneutic vein different to life is the attempt to render transparent these processes and through the rendering to come closer to an understanding of a research encounter in which complex, conflicted, defended, desiring and contextualised subjects meet one another. The re-telling is also grounded in an inner life of anxiety and desire and a relationship, part real, part imagined to the interviewee. ${ }^{1}$ These complex dynamics of association amount in a research situation to 'a counter-transference like' phenomenon, part biographical and part idiomatic and have in the context of the Bromley by Bow research been explored in papers by Froggett \& Chamberlayne (2004) and Froggett \& Wengraf (2004).

\section{Discussion}

A superficial reading of the biographical stories generated at the Bromley by Bow Centre may see a thorny path of progress where adversity is negotiated. The branches are hacked away and the sleeping beauty of social, emotional and material success is

\footnotetext{
${ }^{1}$ These complex dynamics of association amount in a research situation to 'a counter-transference like' phenomenon, part biographical and part idiomatic and have in the context of the Bromley by Bow research been explored in papers by Froggett and Chamberlayne (2004) and Froggett and Wengraf (2004)
} 
discovered at the heart of the thicket. Importantly, the psycho-political gestalt of the hero narrative splits the journey into a 'before' and an 'after' with a defining point, usually the intervention of advisors or professionals, where the former is transformed into the latter. For example, the policy document 'Reaching out: An Action Plan on Social Exclusion', conveys these assumptions when describing the process of intervention:

“...within the tragedy and waste of lifetime and inter-generational exclusion, there is also a message of hope. It is possible, in principle, to identify those most at risk, and to intervene early, holistically and persistently, in order to expand opportunity and tackle the most deep seated forms of exclusion.”

(Cabinet Office, 2006, p.13).

In the field of mental health this before (bad times) and after (good times) description of intervention is particularly striking. For example, when speaking about the encouraging results achieved through cognitive-behavioural therapies a report prepared for the Prime Minister's strategy unit stated,

“Crippling depression and chronic anxiety are the biggest causes of misery in Britain today...we now have evidence-based psychological therapies that can lift at least half of those affected out of their depression or chronic anxiety... half of them could be cured at a cost of no more than $£ 750$ ” (my emphasis).

(LSE, 2006, p.1) 
The language used here would be resisted by many service users and mental health nurses who have stated a preference for the concept of recovery rather than cure (SCMH, 2001; Hurley et al, 2006). The concept of recovery emphasises personal strengths and development over any implied definitive end to symptoms and accommodates within it a complex view of the 'human condition' (Gallop \& Reynods, 2004; Perkins \& Repper, 2004). A ‘curing' intervention is clearly attractive to an NHS under pressure to demonstrate throughput, outcomes and value. However, this resistance by service users and providers to over-simplistic analysis of a health intervention is highly relevant.

Implicit in the rhetoric used to describe cognitive behavioural therapy is not only a clear sense of before and after, but also an assumption that the intervention will be unequivocally positive for the recipient. The belief in a happy resolution has positive elements not least the maintenance of hope during difficult times (Spandler et al, 2007). However, this separating out of experience is also potentially corrosive and of little help in understanding emotional reactions after interventions which lead for example to the commonly reported anti-climax following educational achievement, relapse in addiction and the revolving door syndrome in psychiatry. The narrative is also apolitical. The power and ability to cope are located primarily within the autonomous self-determining individual, who is positioned as being able to freely choose to listen to his/her advisors or not. This means personal progress is dependant upon personal responsiveness and effort, drawing attention away from socioeconomic barriers. 
The biographical stories collected at Bromley by Bow include the perspective of the post liberal subject pursuing the dominant political and cultural goals of autonomy, self-responsibility and progress which are implicit with the hero’s journey narrative. However, the open format and narrative pointed questions of the biographical narrative interpretive interviews also allow more complex and personally meaningful perspectives to emerge and reveal something of why the Centre is capable of combining care with productive social enterprise. For example, when Nell recalls one of the relationships which resulted in her being promoted, she states:

“...it was decided (laughs) for me...how can I put it, he’s a very funny person to work with, an' a very strange person to work with... But 'im an’ I seemed to get on so well.”

Allowing Nell to narrate around the theme of her promotion opens up this area revealing what could be a gendered and generational passivity 'it was decided', but also an ability to empathise and connect with a person others struggle to work with. This skill is understood within the context of Nell's whole biography. Her ability to care for 'strange' others is located in her life-long experiences of not only caring for others, but also of being cared for herself (Froggett \& Chamberlayne, 2004). This view of the processes which underpin the centre's success challenges the linear, outcome focused nature of the hero narrative and instead illuminates a view whereby previous experience is carried within the person and is seen as the ground on which ‘success' can be built.

\section{Conclusions}


This paper suggests that when evaluating projects like Todmorden Touchwood and the Bromley by Bow Centre, successful or preferred outcomes need to be conceived as being in an interdependent relationship with what are seen as failures. In both projects storytelling generates an inclusive view of community, because it draws out different, often opposing strands and allows their co-existence within the framework of a narrative that can be shared. If the narrative itself had merely perpetuated a wider socially and economically sanctioned discourse of progress, then the thrust would have been towards social conformism and oppression of those who by virtue of capacity or circumstance could not readily identify as 'heroic'. These projects have demonstrated how the hero's journey narrative can be resisted in subtle but significant ways by those who engage in storytelling as they search for meaningful personal and mythical narratives which resonate with their own experiences. The stories in both the projects reported here hold within themselves the ambiguity and complexity of experience and it is here that they generate the open and questioning frames of mind and the moral learning that resist pejorative ascriptions of otherness and social exclusion. The qualitative evaluations of these projects have also demonstrated how narrative methods and a reflexive receptivity towards stories can make a powerful contribution to methodologies aimed at exploring excluded experiences and perspectives which are rarely admitted to the mainstream.

When responding to repeated accusations that 'The Golden Notebook' was a feminist diatribe, Doris Lessing identified the ubiquitous nature of this cultural sanctioned drive towards separation, stating: 
“...from the very beginning the child is trained to think in this way: always in terms of comparison, of success, and of failure. It is a weeding-out system: the weaker get discouraged and fall out; a system designed to produce a few winners who are always in competition with each other”.

(Lessing, 1971, Preface to 'The Golden Notebook, p.15)

The tendencies described by Lessing have intensified and become galvanised within contemporary culture. The ‘introduction - complication/intervention - resolution' narrative is dominant, with an explicit emphasis that resolution should be rooted in 'good' economically productive activities (FSE, 2006). The interventionist rhetoric that is explicit in government policy (Blair, 2006a) is congruent with a simplistic version of the hero's journey narrative. Positioning a successful resolution as some sort of absolute state, and therefore separating it out from what has preceded it seems misleading in the least and at worst damaging as negative emotions following the intervention become difficult to process leaving the door open for high levels of selfblaming.

Storytelling yields intrinsically psychosocial perspectives in that it has an ability to imaginatively represent the internal world as well as the social circumstances of the 'other', allowing recognition and subsequent representation of the 'whole person situation’ (Froggett \& Chamberlayne, 2004). Although it can shore up social and political conformism much contemporary storytelling tries to promote a cultural egalitarianism that is more likely to inspire a critical consciousness. As a research method it helps resist reductive analysis, and sheds light on how personal endeavour is located in interdependency. Whether it is used to engage diverse communities or 
render social and biographical experience in research storytelling has the potential to gain access to the complexity of both individual and shared realities in a way other methods struggle to achieve.

References:

Andrews, M. (2000) Texts in a changing context: Reconstructing lives in East

Germany. In. P. Chamberlayne., J. Bornat. \& T. Wengraf. (Eds.) (2000) The Turn to Biographical Methods in Social Science. London: Routledge

Blair, T. (2006) Prime Minister’s Preface. in. Cabinet Office (2006) Reaching Out: An Action Plan on Social Exclusion. London: Cabinet Office.

Blair, T. (2006a) Prime Minister’s Forward. In. Home Office (2006) Respect Action Plan. London: Respect Task Force

Boal, A. (1985) Theatre of the Oppressed. New York: Theatre Communications Group

Bollas, C. (1995) Cracking up: The work of unconscious experience. London: Routledge

Bowker, J. ed. (1997) The Oxford Dictionary of World Religions. Oxford: Oxford University Press

Brickell, P. (2000) People Before Structures: Engaging Communities Effectively in Regeneration. London: Demos

Bruner, J. (1986) Actual minds, possible worlds. Cambridge MA: Harvard University Press

Bruner, J. (1990) Acts of Meaning. London: Harvard University Press 
Cabinet Office (2006) Reaching Out: An Action Plan on Social Exclusion. London: Cabinet Office

Chase, S.E. (2005) Narrative Inquiry: Multiple lenses, approaches, voices. In. N.K. Denzin. \& Y.S. Lincoln. Eds. (2005) The Sage Handbook of Qualitative Research. London: Sage Publications.

DH (2006) Health Profile for Calderdale 2006. London: Department of Health Ensler, E. (2001) The vagina monologues: The V-day edition. New York: Villard/Random House

Froggett, L. \& Chamberlayne, P. (2004) Narratives of Social Enterprise: From biography to practice and policy critique. Qualitative Social Work. Vol.3(1). pp.61-77 Froggett, L., and Wengraf, T. (2004) Interpreting interviews in the light of research team dynamics: a study of Nila’s biographic narrative. Critical Psychology Vol. 10 Gallop, R. \& Reynolds, W. (2004) Putting it all together: dealing with complexity in the understanding of the human condition. Journal of Psychiatric and Mental Health Nursing. Vol.11(3) p.357

Greenwood, D.J. \& Leven, M. (2005) Reform of the Social Sciences and of Universities through Action Research. In. N.K. Denzin. \& Y.S. Lincoln. Eds. (2005) The Sage Handbook of Qualitative Research. London: Sage Publications.

Grima, B. (1991) The role of suffering in women’s performance of paxto. In. A. Appadurai., F.J. Korom, \& M.A. Mills. (Eds.) Gender, genre and power in South Asian expressive traditions. Philadelphia: University of Pennsylvania Presss. Hurley, J., Barrett, P. \& Reet, P. (2006) ‘Let a hundred flowers blossom, let a hundred schools of thought contend': a case for therapeutic pluralism in mental health nursing. Journal of Psychiatric and Mental Health Nursing. Vol.13(2) p.173 
Lessing, D. (1971) Preface to 1972 edition of 'The Golden Notebook'. In D. Lessing (1972) The Golden Notebook. London: Harper Perennial.

London School of Economics (LSE) (2006) The Depression Report: A New Deal for Depression and Anxiety Disorders. The centre for economic performance's mental health policy group. London: LSE

ODPM (2004) The English Indices of Deprivation 2004 (revised). London: Office of the Deputy Prime Minister Publications.

ONS (2001) 2001 Census: Census Area Statistics. London: HMSO

Perkins, R. \& Repper, J. (2004) Rehabilitation and Recovery. In I. Norman \& I. Ryrie (eds) (2004) The Art and Science of Mental Health Nursing: A textbook of principles and practice. Maidenhead: Open University Press.

Polanyi, M. (1966) The Tacit Dimension. Reprinted (1983) USA: Doublday \& Company inc.

Polkinghorne, D.E. (1988) Narrative Knowing and the Human Sciences. New York: State University of New York Press.

Sainsbury Centre for Mental Health. (2001) User's Voices. The perspectives of mental health service users on community and hospital care. London: The Sainsbury Centre for Mental Health

Schütze, F. (1984) ‘Kognitive Strukturen autogiographischen Stegreiferzählens’, in M.Kohli and G. Robert (eds), Biographie und sziale Wirklichkeit: Neue Beiträge und Forschungsperspektiven. Stuttgart: Metzler, pp.78-117

Spandler, H., Secker, J., Kent, L., Hacking, S. \& Shenton, J. (2007) Catching Life: the contribution of arts initiatives to recovery approaches in mental health. Journal of Psychiatric and Mental Health Nursing. 14 (8) pp.791-799

Wengraf, T. (2001) Qualitative Research Interviewing. London: SAGE Publications 
Wilson, M. (2006) Storytelling and theatre: contemporary storytellers and their art. Basingstoke: Palgrave Macmillan Young, M. (2000) Inclusion and Democracy. Oxford: Oxford University Press Zipes, J. (2006) The Possibility of Storytelling and Theatre in Impossible Times. In M. Wilson. (2006) Storytelling and theatre: contemporary storytellers and their art. Basingstoke: Palgrave Macmillan 